http://jmscr.igmpublication.org/home/ ISSN (e)-2347-176x ISSN (p) 2455-0450 crossref DOI: https://dx.doi.org/10.18535/jmscr/v7i11.04

\title{
Single Centre Experience of Mitral Valve Surgeries in the Young
}

\author{
Authors \\ Dr Sistla VPL Chandrakumar ${ }^{1}$, Dr Khushwant Popli ${ }^{2 *}$, Dr Kunwar Sidharth Saurabh ${ }^{3}$, \\ Dr Ridhika Munjal ${ }^{4}$, Dr Anubhav Gupta ${ }^{5}$ \\ ${ }^{1,3,4}$ Senior Resident, CTVS, VMMC \& SJH, Delhi \\ ${ }^{2}$ Assistant Professor, CTVS, VMMC \& SJH, Delhi \\ ${ }^{5} \mathrm{HOD}, \mathrm{CTVS}, \mathrm{VMMC} \& \mathrm{SJH}$, Delhi \\ *Corresponding Author \\ Dr Khushwant Popli \\ Assistant Professor, CTVS, VMMC \& SJH, Delhi, India
}

\begin{abstract}
Valvular heart disease is an important cause of morbidity and mortality worldwide. In India, Rheumatic heart disease is an important cause of valvular heart disease. We tried to analyse pattern of mitral valve disease and the surgeries we performed in individuals younger than 18 years presenting to our institute.

Methods: Retrospectively we analysed the data of patients aged less than 18 years, who underwent mitral valve surgeries in our institute between September 2017 to September 2018, with one year follow up. Analysed the data with respect to age, gender, type of valvular heart disease, if it is single or multiple valves that is affected, type of surgery-repair or replacement and immediate postoperative complications if any and during the follow up.

Results: Out of 24 patients, 22 underwent valve replacement. Two underwent valve repair successfully. One patient with failed repair had to undergo revision for valve replacement. Subset of the population we operated presented with severely diseased valves that prevented successful valve repair.
\end{abstract}

\section{Introduction}

All patients younger than 18 years who underwent mitral valve surgeries at our centre from September 2017 to September 2018 were analysed with respect to demography, etiology, presentation and surgery they underwent. We had 24 patients in this age group. The median age is 15 , The youngest one was 6 years old, the eldest was 18 years. Four were females. Four cases were of congenital etiology. Excluding congenital causes, the rest were of rheumatic etiology. One patient who had congenital MR had a LA to RV fistula at the apex of AML cleft. In another case of congenital MR, neochordae was constructed. One case of congenital MR was associated with ostium primum ASD with a cleft in AML. Eight of our patients had multi-valvular disease. MR was the predominant lesion with only 2 cases of isolated MS and five cases of combined MS, MR. Eleven cases had associated aortic valve disease from 
mild to severe AS/ AR with seven patients requiring double valve replacement. Those who required DVR, ranged from 14 to 18 years. Tricuspid valve disease was associated in twenty of twenty-four patients. But only six required TV repair. Of the patients with MR, eight had prolapse of A2-3 segments. One case each had cleft in AML and PML. Eight of our cases, we tried repairing mitral valve, but only in two, the repair was successful. In the rest, we had to replace the valve. Rheumatic etiology, subvalvar disease with thickened chordae, prevented repair. Most patients in our series had normal sinus rhythm. AF was found in four of patients, all with MR. All the four with AF had their LAes> 50 $\mathrm{mm}^{2}$.Of the patients who underwent valve replacements, the smallest size used was $25 \mathrm{~mm}$ and the largest size used was $33 \mathrm{~mm}$ St Jude Master series mechanical valve. The median size of the valve is 27. Most frequently used valve was $27 \mathrm{~mm}$ St Jude Master series mechanical valve, and youngest to receive this valve was 10year-old while the eldest was 17-year-old.

\section{Immediate Postoperative Period}

Routine postoperative ECHO demonstrated more than moderate MR in one patient, she required reoperation and mitral valve replacement. We had one early mortality in our series, where in low cardiac output syndrome after MVR for severe MR was the cause.

\section{Follow-up}

We report the follow up at one year from the date of discharge. In patients who underwent mitral valve repair, no residual regurgitation. None, in our series had patient prosthesis mismatch. We calculated the EOA using the continuity equation and found the EOA > 1.2, which rules out any PPM. Of the six patients who had Tricuspid repair, mild TR was reported in four, moderate in one and none in one. One patient was readmitted for rate control. The other three patients with atrial fibrillation continued to be in AF, though with a controlled rate. No patient in our series had thromboembolic complication. No patient developed DSWI in our series in this age group.

\section{Age and Sex distribution}

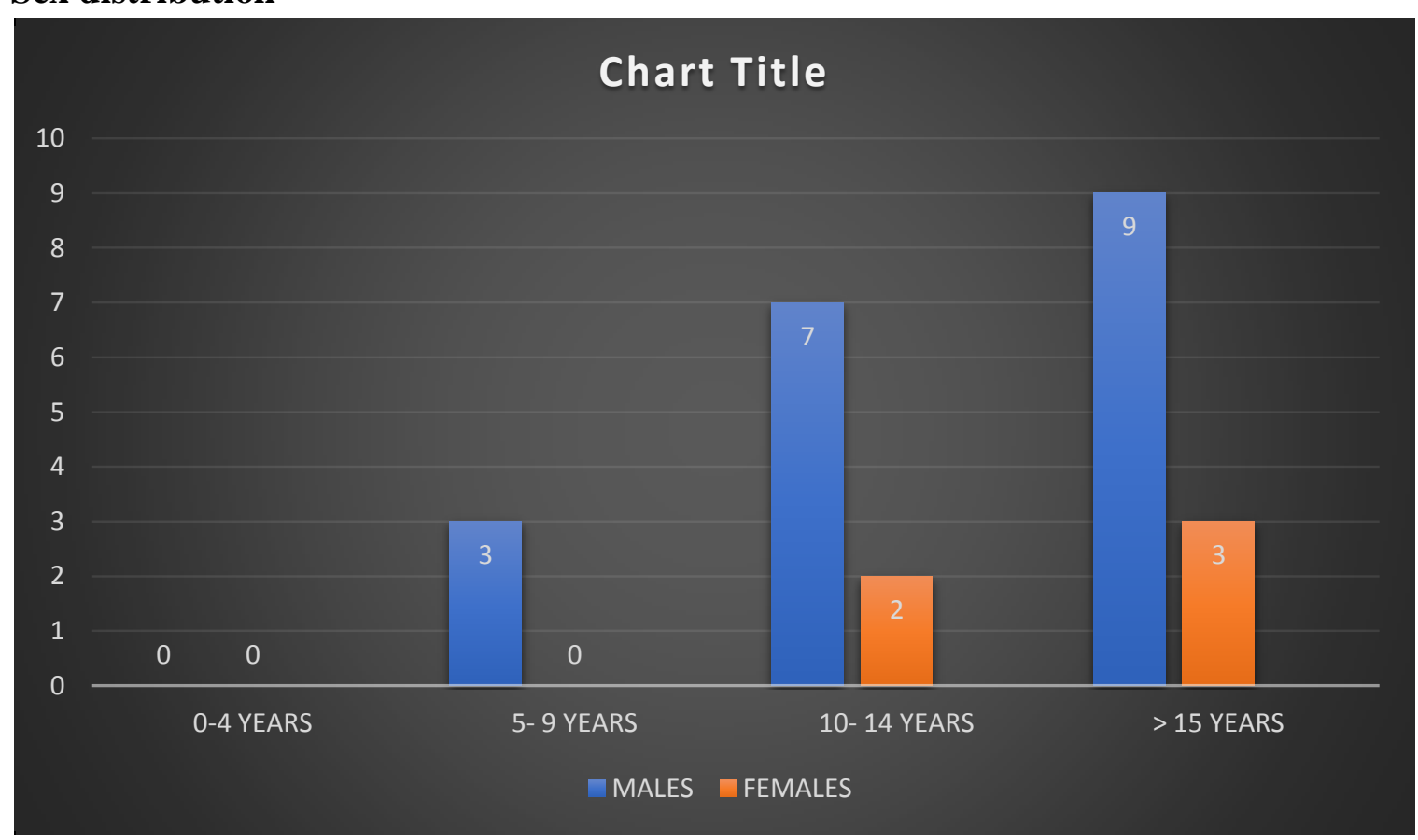


Associated lesions

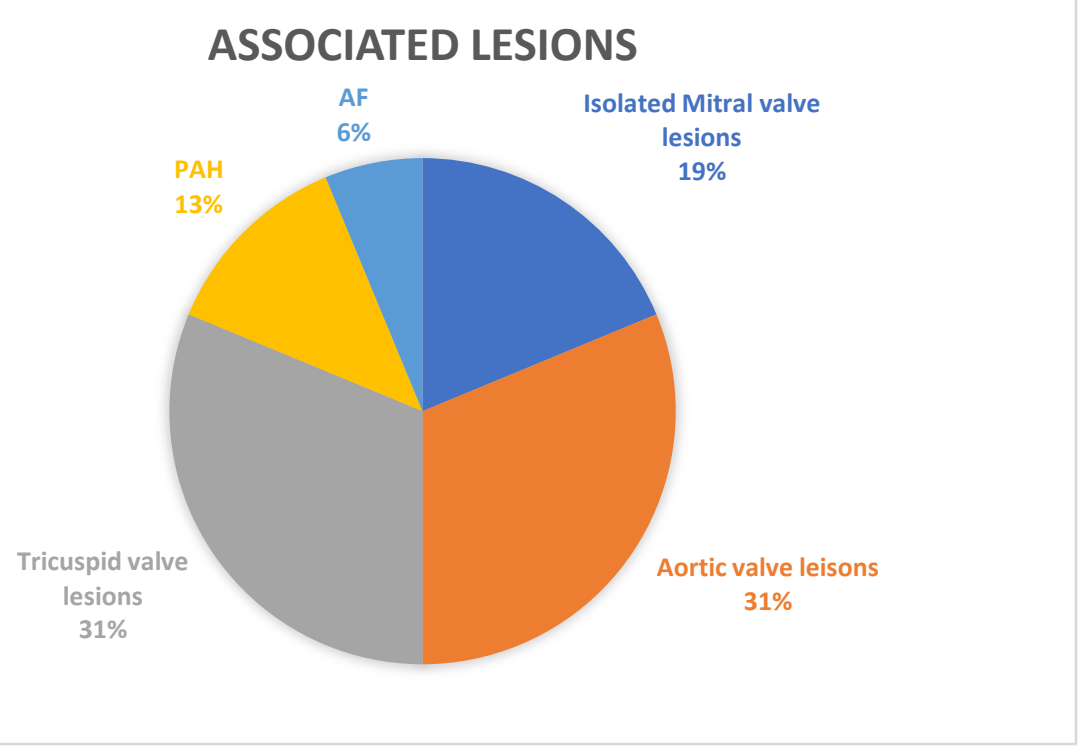

Severity of preoperative TR in our series

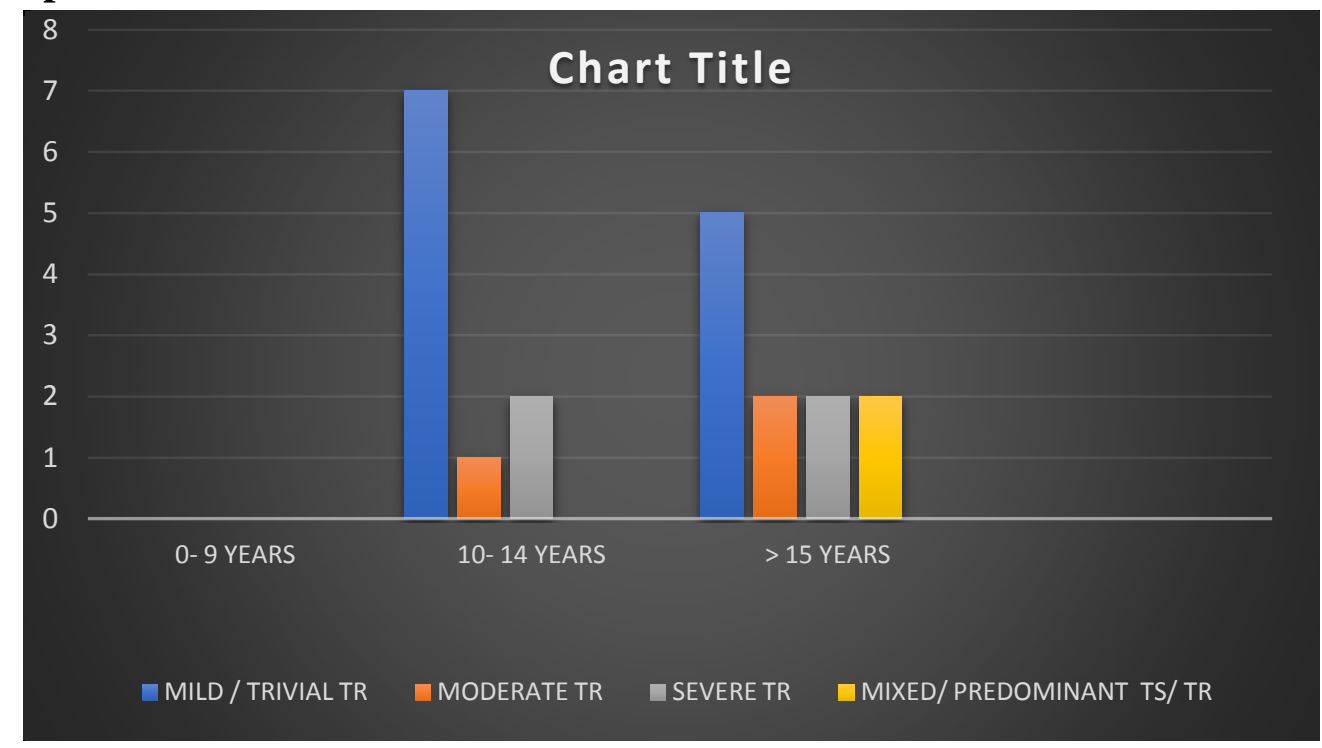

Prosthetic valve size used

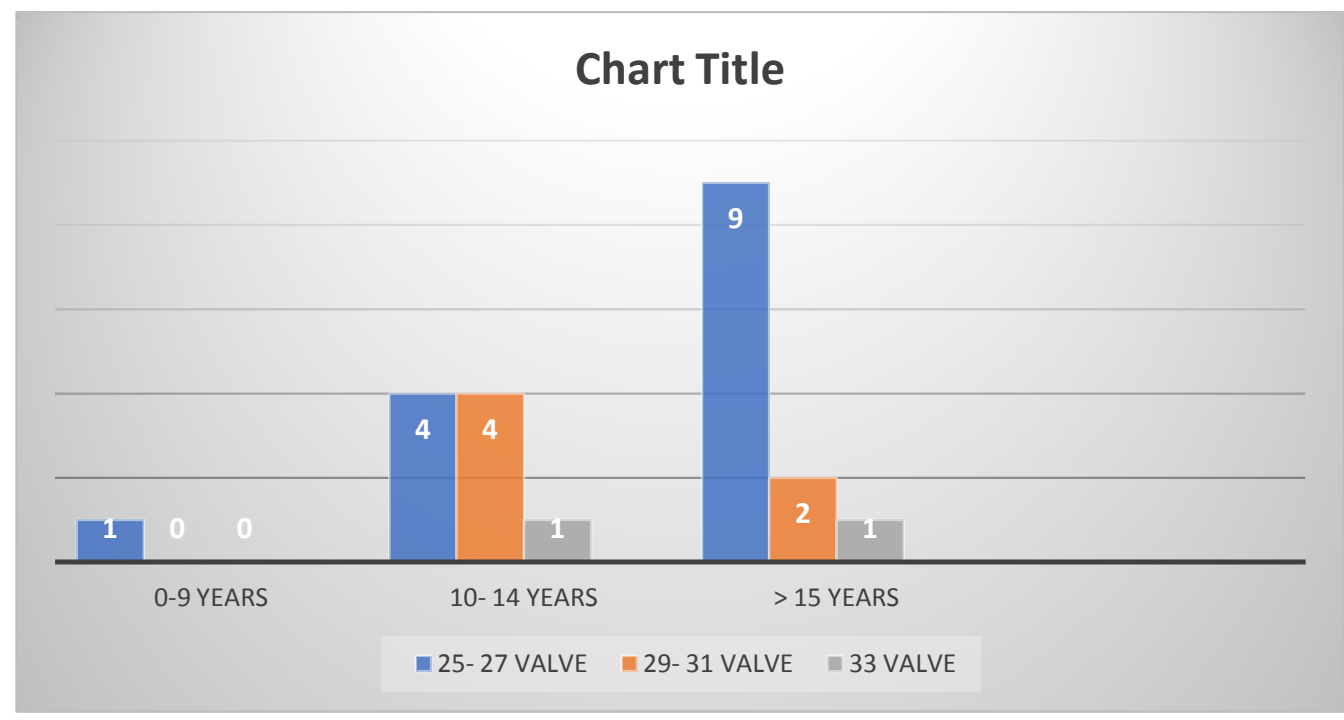


Table: Different sizes of valves, age group, follow-up in our series

\begin{tabular}{|l|c|c|c|c|c|}
\hline Valve size & $\mathbf{2 5} \mathbf{~ m m}$ & $\mathbf{2 7} \mathbf{~ m m}$ & $\mathbf{2 9} \mathbf{~ m m}$ & $\mathbf{3 1} \mathbf{~ m m}$ & $\mathbf{3 3} \mathbf{~} \mathbf{m}$ \\
\hline No of patients & 6 & 8 & 4 & 2 & 2 \\
\hline Min age of the patient & 9 years & 10 years & 13 years & 12 years & 13 years \\
\hline Max age of the patient & 17 years & 18 years & 17 years & 14 years & 18 years \\
\hline PPM during follow up & None & None & None & None & None \\
\hline Prosthetic valve thrombosis & None & None & None & None & None \\
\hline MACE/ non- MACE & None & None & None & None & None \\
\hline
\end{tabular}

\section{Discussion}

In the young patients, mitral valve surgery poses a situation different from adults. Placement of a large prosthesis in children with small mitral annulus is associated with high risk for operative mortality due to complications related to leaflet entrapment, development of left ventricular outflow tract obstruction, tricuspid valve obstruction and conduction block. Replacement in this age group has a high operative mortality ranging from $10 \%$ to $36 \%$, in addition to significant morbidity.

The use of homografts and bioprosthetic valves for aortic or mitral valve replacement in children is associated with rapid structural degeneration and eminent reoperation requirement. As bioprosthetic valves are not available in small sizes, mechanical valves are the main replacement option in young children in whom a small prosthesis is required.

MV repair is desirable and should be attempted because it conserves the subvalvar apparatus and ventricular geometry, preserving left ventricular function. Preserved left ventricular function leads to survival benefits in the long term. Several groups have reported satisfactory results with MV repair in children with mid- to long-term survival of $77-94 \%$.

\section{Biodegradable rings for annuloplasty in children $^{5}$}

One of the options for mitral valve repair in young children who require annuloplasty rings of less than $26 \mathrm{~mm}$, where no commercially available rings are available, biodegradable rings are a good option. Kalangos et al reported first use of biodegradable rings in animals. Bautista- Hernandez, reported the use of biodegradable rings in six children and showed that these rings promotes annular remodelling and maintains the growth potential of the native annulus. Biodegradable ring used here is PDS.

Techniques available for repair of mitral valve ${ }^{4}$

\begin{tabular}{|c|c|}
\hline Mitral stenosis & Mitral regurgitation \\
\hline Commissurotomy & Wooler- Kay annuloplasty \\
\hline Papillary muscle splitting & Cleft repair \\
\hline $\begin{array}{l}\text { Resection of supravalvular } \\
\text { ring }\end{array}$ & Strip annuloplasty \\
\hline $\begin{array}{l}\text { Resection of secondary } \\
\text { chordae }\end{array}$ & Ring annuloplasty \\
\hline Fenestration of chordae & Artificial chordae \\
\hline \multirow[t]{7}{*}{ Slicing of leaflet } & Chorade shortening \\
\hline & Posterior annulus splitting \\
\hline & Papillary muscle splitting \\
\hline & $\begin{array}{l}\text { Resection of secondary } \\
\text { chordae }\end{array}$ \\
\hline & Edge to edge repair \\
\hline & Commissure obliteration \\
\hline & Chordal transfer \\
\hline
\end{tabular}

\section{Transcatheter procedures for mitral valve repair $^{6}$}

Over the last decade, several transcatheter mitralvalve repair technologies adapted from different surgical techniques have emerged for treating MR inpatients at high or prohibitive surgical risk. The transcatheter mitral valve repair "tool box" is rapidly expanding, with up to 5 devices already approved in Europe, including the MitraClip (Abbott Vascular, Inc., Santa Clara, California), the DS1000 device (Neo Chord, Inc., St. Luis Park, Minnesota), the Carillon (Cardiac Dimensions, Inc., Kirkland, Washington), the Cardio Band (Valtech Cardio, Or Yehuda, Israel), and the Mitralign device (Mitralign, Inc., Tewksbury, Massachusetts). In current practice, transcatheter mitral valve repair is mainly limited to the Mitra Clip device, which mimics the edgeto-edge leaflet repair described by Alfieri et al. Since the introduction of Mitra Clip in 2003, more 
than 35,000 patients have been treated with high success and safety rates, translating into some degree of functional improvement in most patients ${ }^{5}$.

\section{Conclusion}

Mitral valve is diseased due to multitude of causes. In India, rheumatic heart disease continues to be the most common cause. Congenital causes of mitral valve disease account for a significant cause after RHD. Because valvular heart disease of RHD etiology is associated with severe subvalvular disease, mitral valve repair is not always possible. In our study population, patients from low socio-economic strata, with low educational status, comprise most of the patients. Inadequacy of initial treatment of acute rheumatic fever, delay in seeking medical aid after establishment of RHD, delayed referrals for surgery, all account for delayed presentation with extensive subvalvular disease beyond possibilities of repair. But repair should be attempted in every case of VHD as and when possible. Comparison of world literature shows valve repairs taking upper hand over replacement. But when repair is not possible, of whatever cause, every attempt should be made to facilitate normal growth of the annulus with age. Biodegradable rings instead of routine annuloplasty rings are a good alternative. Transcatheter procedures are rapidly gaining popularity and can be suitable alternatives to surgical valve replacements, in the adults. In pediatric age group, there is insufficient data to recommend transcatheter procedures. We conclude that even though mitral valve repair takes precedence over replacement in the young individuals, valve replacement is not a bad option where repair is not possible.

\section{Reference}

1. SK Sharma, SH Verma, A clinical evaluation of atrial fibrillation in Rheumatic Heart Disease, Journal of The Association of Physicians of India, Vol 63, June 2015.

2. Raghavendra Mariyamballi, Nalina Thimmappa et al, CORRELATION OF LEFT ATRIAL SIZE AND ATRIAL FIBRILLATION IN RHD WITH MITRAL VALVE DISEASE J. Evolution Med. Dent. Sci./ eISSN- 2278-4802, pISSN- 2278-4748/ vol.05/ issue 19/ Mar. 07, 2016

3. Avinoam Shiran, MD, Alex Sagie, MD et al, Tricuspid Regurgitation in Mitral Valve Disease Incidence, Prognostic Implications, Mechanism, and Management, Journal of American College of Cardiology, Vol 53, No. 5, 2009

4. Cheul Lee, Chang-Ha Lee et al, long term results of mitral valve repair in children, European Journal of Cardio-thoracic Surgery 37 (2010) 267-272

5. Mohd. Azhari Yakub, Sivakumar Sivalingam et al, Mitral Valve Repair for Congenital Mitral Valve Disease: Impact of The Use of A Biodegradable Annuloplasty Ring, Ann of Thoracic Surgery 2015;99:884-90

6. Ander Regueiro MD, Juan F. Granada et al, Transcatheter Mitral Valve Replacement, Journal of The American college of Cardiology, Vol. 69, No.17, 2017. 